\title{
Chemical Constituents and Bioactivity Studies of Ardisia Elliptica
}

\author{
Nurul Zawani Alias* and Nur Kamisah Mohd Ishak
}

Faculty of Applied Sciences, Universiti Teknologi MARA (Perlis), 02600 Arau, Perlis, Malaysia

\begin{abstract}
Ardisia elliptica is a medicinal plant traditionally used for alleviating chest pains, treatment of fever, diarrhea, liver poisoning and for parturition complications. The objectives of this study were to investigate the chemical constituents in fruits and leaves extracts of A. elliptica and to determine the biological activities of these extracts. The fruits and leaves of $A$. elliptica were soaked with methanol and the extracts were analysed using GCMS. Both extracts were then tested for antibacterial activity using disc diffusion method against Staphylococcus aureus (gram positive) and Escherichia coli (gram negative). After incubation for 24 hours, the inhibition zones of the extracts were compared with gentamicin and ampicilin. Antioxidant activities were determined using DPPH and analysed by Spectronic-20 with wavelength of $517 \mathrm{~nm}$. From GCMS data, it was found that both extracts contained similar major compound which were 5-hydroxymethyl-2-furancarboxaldehyde with percentage area of 58.42\%, and $45.13 \%$; 2,4-di-tert-butylphenol with $3.04 \%$ and $20.87 \%$ and clindamycin with $8.77 \%$ and $5.79 \%$ for fruits and leaves extracts respectively. Clindamycin is a known antibiotic therefore both extracts showed positive result for antibacterial tests. Antioxidant assay also showed that both fruits and leaves extracts decolorized the DPPH.
\end{abstract}

Keywords: Ardisia elliptica, Clindamycin, DPPH.

\section{INTRODUCTION}

The genus of Ardisia is the largest genus in the family of Myrsinaceae. The usage of Ardisia as a source of food and medicine is rather limited. It appears that berries of at least few species, such as A. elliptica Thunb. and A. macrocarpa, a Himalayan species, have been used for human consumption [1,2]. Johnson (1998) listed 15 identified and one unidentified species of Ardisia along with their medicinal properties and some ailments and conditions including cancer (A. cornudentata), diarrhea (A. crispa, A. odontophylla and $A$. villosa), hepatosis ( $A$. villosa), parturition (A. ridleyi) and rheumatism (A. crassa, A. crispa, A. odontophylla and A. villosa) [3].

Ardisia elliptica also known as shoebutton Ardisia. Local name of A. elliptica is Mata Pelanduk or Mata Ayam which is a native medicinal plant commonly found in Malay Peninsula [4]. It is an invasive shrub or small tree to $6 \mathrm{~m}$ in height and $15 \mathrm{~cm}$ in basal diameter. The plants produce strong stems with grey bark. The stem are usually single, but additional sprout may arise from the rootstalk, especially if the plant in injured. A. elliptica grows a strong taproot, much branched laterals, and fine roots with rhizomorphic tips. Leaves have a rubbery or leathery texture and are pink when young, turning dark green later. They are glabrous and alternate with petioles about $1 \mathrm{~cm}$ long and blades 8 to $12 \mathrm{~cm}$ by about $3 \mathrm{~nm}[5]$.

A. elliptica is traditionally used for alleviating chest pains, treatment of fever, diarrhea, liver poisoning, and

\footnotetext{
*Address correspondence to this author at the Faculty of Applied Sciences, Universiti Teknologi MARA (Perlis), 02600 Arau, Perlis, Malaysia;

E-mail: zawani299@perlis.uitm.edu.my
}

parturition complications. The decoction of the leaves of this species is used by the Malays for treatment of pain in the region of the heart or to alleviate chest pains [6, 7]. According to Jianhong et al. (2010), A. elliptica is more potent than aspirin in inhibiting collagen-induced platelet aggregation by $\alpha$ - and $\beta$-amyrin contain in this herbs. This compound is responsible to alleviate the chest pain and head disease [8].

Based on Hideka and Elvira (2004), A. elliptica has antibiotic and antiviral properties. The phytochemical compound contained in A. elliptica leaves are Bauerenol, $\alpha$ and $\beta$-amyrin and Bergenin. Bergenin is an isocoumarin found in various plant species and exhibits a wide range of biological activites including hepatoprotective, antifungal, anti-HIV, antiarrhythmic and hypolipidemic [9].

Even though there are a number of reported studies of this species, the studies on chemical components of $A$. elliptica extracts are limited. Therefore, this study would contribute on the chemical constituents of this species and the antibacterial and antioxidant activities of the extract.

\section{EXPERIMENTAL}

\section{Collection of Sample}

Fresh leaves and fruits of Ardisia elliptica were collected from Lubuk Merbau, Kuala Kangsar in July 2012. The samples were packed in plastic bag and kept in temperature of $\pm 4{ }^{\circ} \mathrm{C}$ until extraction.

\section{Extraction}

Fruits and leaves of Ardisia elliptica were weighed (10 g) and cut into small pieces. The samples were transferred into Erlenmeyer flask and were soaked with $200 \mathrm{ml}$ of methanol 
Table 1. The Chemical Constituents of Leaves Extract of $A$. elliptica.

\begin{tabular}{|c|c|c|c|}
\hline Peak & Retention Time, $\mathbf{t}_{\boldsymbol{R}}$ & Compound Name & Percent Abundance $\%$ \\
\hline \hline 1 & 1.889 & 2-methoxy-1-(2-nitroethenyl)-3-benzene & 1.06 \\
\hline 2 & 3.608 & Chlorfenapyr & 6.74 \\
\hline $\mathbf{3}$ & $\mathbf{6 . 8 0 0}$ & Clindamycin & $\mathbf{5 . 7 9}$ \\
\hline 4 & 7.377 & Decamethyl-cyclopentasiloxane & $\mathbf{1 2 . 4 1}$ \\
\hline $\mathbf{5}$ & $\mathbf{7 . 7 1 0}$ & 1-naphthyl ester acetoxyacetic acid & $\mathbf{4 5 . 1 3}$ \\
\hline $\mathbf{6}$ & $\mathbf{8 . 5 7 8}$ & $\mathbf{5 - h y d r o x y m e t h ~ 2 - f u r a n c a r b o x a l d e h y d e}$ & 0.56 \\
\hline 7 & 10.404 & Methyl 3-amino-2-thiophenecarboxyldehyde & 6.08 \\
\hline 8 & 11.30 & 4-cyanophenyl 2,6-difluorobenzoic acid & $\mathbf{2 0 . 8 7}$ \\
\hline $\mathbf{9}$ & $\mathbf{1 1 . 5 0 1}$ & $\mathbf{2 , 4 - b i s ( 1 , 1 - d i m e t h y l e t h y l ) - p h e n o l}$ & 99.99 \\
\hline
\end{tabular}

Table 2. The Chemical Constituents of fruits Extract of $\boldsymbol{A}$. elliptica.

\begin{tabular}{|c|c|c|c|}
\hline Peak & Retention Time, $\mathbf{t}_{\boldsymbol{R}}$ & Compound Name & Percent Abundance\% \\
\hline \hline 1 & 1.908 & 2-methoxy-1-(2-nitroethenyl)-3-benzene & 0.92 \\
\hline $\mathbf{2}$ & $\mathbf{6 . 7 8 5}$ & Clindamycin & $\mathbf{8 . 7 7}$ \\
\hline 3 & 7.363 & Decamethyl-cyclopentasiloxane & $\mathbf{1 6 . 9 0}$ \\
\hline $\mathbf{4}$ & $\mathbf{7 . 6 9 1}$ & $\mathbf{1 - n a p h t h y l ~ e s t e r ~ a c e t o x y a c e t i c ~ a c i d ~}$ & $\mathbf{5 8 . 4 2}$ \\
\hline $\mathbf{5}$ & $\mathbf{8 . 5 6 5}$ & $\mathbf{5 - h y d r o x y m e t h ~ 2 - f u r a n c a r b o x a l d e h y d e}$ & 5.16 \\
\hline 6 & 9.165 & Dodecamethyl-cyclohexasiloxane & 2.38 \\
\hline 7 & 10.866 & tetradecamethyl-cyclohexasiloxane & 0.39 \\
\hline 8 & 11.282 & Tridec-2-ynyl 2.6-difluorobenzoic acid & $\mathbf{3 . 0 4}$ \\
\hline $\mathbf{9}$ & $\mathbf{1 1 . 5 0 1}$ & $\mathbf{2 , 4 - b i s ( 1 , 1 - d i m e t h y l e t h y l ) - p h e n o l}$ & 100.01 \\
\hline
\end{tabular}

for 4 days. The extracts were filtered and further concentrated and stored at $\pm 4{ }^{\circ} \mathrm{C}$.

\section{Gas Chromatography Mass Spectrometry}

The extracts were analyzed using Varians GC-MS. The oven temperature was programmed from $70{ }^{\circ} \mathrm{C}$ to $180{ }^{\circ} \mathrm{C}$ at $4{ }^{\circ} \mathrm{C} / \mathrm{min}$. The solvent used was hexane $>95 \%$ analyses grade with helium as the carrier gas and split ratio was 1:50. The ionization voltage was $70 \mathrm{eV}$ with the ion source temperature of $280{ }^{\circ} \mathrm{C}$ and mass range of $30-300$ mass units.

\section{Antioxidant Test}

From each sample, different concentrations of essential oils were prepared in ethanol: 20, 40, 60 and $80 \mathrm{ppm}$. The antioxidant activity of essential oils was carried out using free radical scavenging activity using DPPH. $3 \mathrm{ml}$ of DPPH solution was added to $3 \mathrm{ml}$ of extract solution of different concentrations. The absorbance was measured at $517 \mathrm{~nm}$ in a spectrophotometer Spectronic-20. The DPPH radical concentration was calculated using the following equation: Scavenging effect $\%=[(\mathrm{A} 0-\mathrm{A} 1) / \mathrm{A} 0] * 100$ where A0 was the absorbance of the control sample (without essential oil) and A1 was the absorbance in the presence of the sample.

\section{Antibacterial Test}

Antibacterial activity of fruits and leaves extracts was determined by disc diffusion method on nutrient agar medium. Staphylococcus aureus (gram positive bacteria) and Escherichia coli (gram negative bacteria) were used. The bacteria $(400 \mu \mathrm{L})$ were transferred into the petri dish using micropipette $(1000 \mu \mathrm{L})$ and were spread equally on the medium using stirrer. The stirrer was soaked in alcohol, heated and then cools in the laminar flow before applied to the medium containing the bacteria. Then $10 \mu \mathrm{L}$ of each solvent extract was placed in the paper disc. The treatments also included $10 \mu \mathrm{L}$ of solvent (methanol) served as control and the standard control were ampicilin and gentamicin. Then, the plates were sealed using parafilm and were incubated at $37^{\circ} \mathrm{C}$ (room temperature) for 24 hours. The inhibition zone around the paper disc was measured in $\mathrm{mm}$ (milimeter).

\section{RESULTS AND DISCUSSION}

Chemical constituents of leaves and fruits extracts were determined using GCMS. Percent yield of leaves and fruits extracts were 40.56 and $54.30 \%$ respectively. The identified chemical constituents were listed in Tables $\mathbf{1}$ and $\mathbf{2}$ and were 


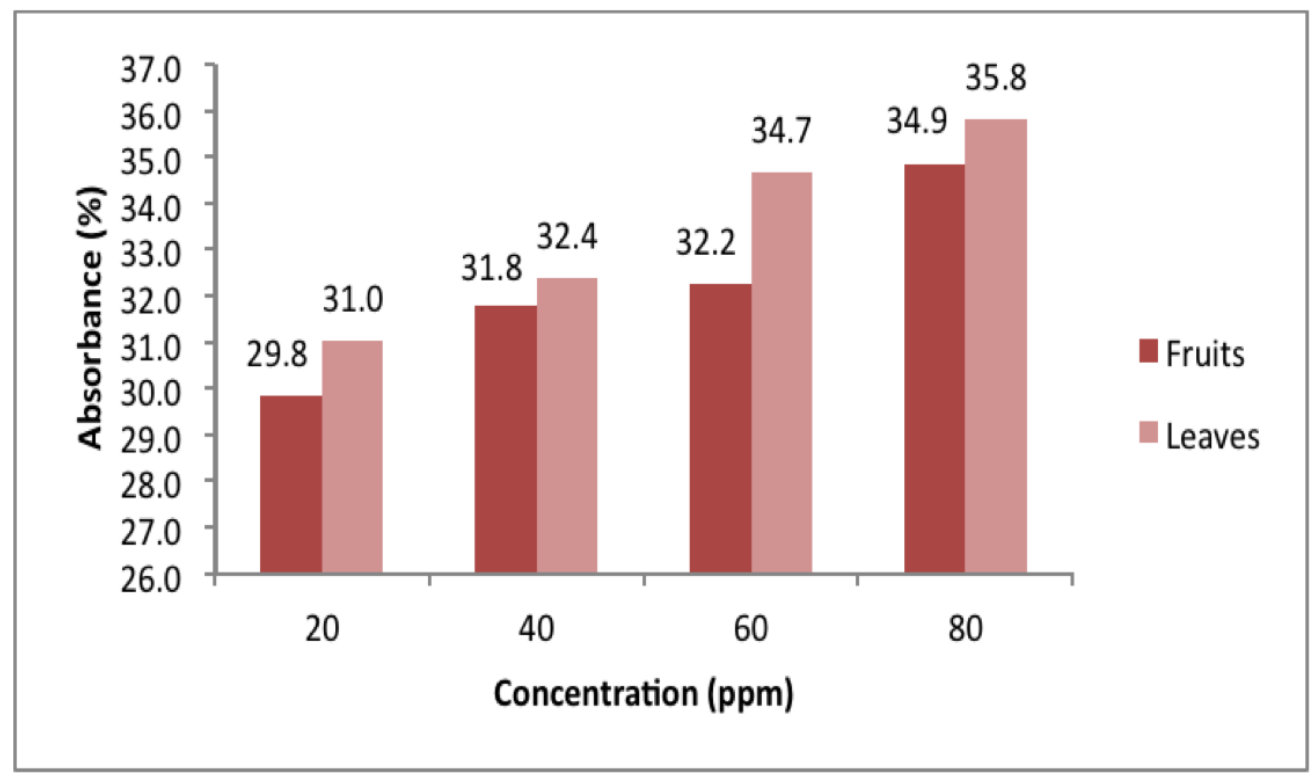

Fig. (1). DPPH scavenging activity of different concentrations of fruits and leaves extracts of $A$. elliptica.

constituted of $99.99 \%$ for leaves and $100.01 \%$ for fruits extracts.

The major compounds for leaves extracts were 1naphthyl ester acetoxyacetic acid (1) (12.41\%), 5hydroxymeth-2-furancarboxaldehyde (2) (45.13\%) and 2,4bis(1,1-dimethylethyl)-phenol (3) (20.87\%). In addition, clindamycin, an antibiotic used to treat anaerobic infections was found with percent abundance of $5.79 \%$. Fruits extracts showed almost similar results with 1-naphthyl ester acetoxyacetic acid (16.90\%), 5-hydroxymeth-2-furancarboxaldehyde $(58.42 \%)$, and clindamycin $(8.77 \%)$ as the major constituents. 2,4-bis(1,1-dimethylethyl)-phenol which is responsible for antioxidant activity was also found in fruits extracts. The major and active compound are higher in percentage in fruits extracts except for 2,4-bis(1,1dimethylethyl)-phenol.<smiles>C=C(C)Oc1ccc2ccccc2c1-c1c(OC(C)=O)ccc2ccccc12</smiles><smiles>O=Cc1ccc(CO)o1</smiles><smiles>CC(C)(C)c1cccc(C(C)(C)C)c1O</smiles>

\section{Antioxidant Assay}

Fig. (1) showed the antioxidant activity of leaves and fruits extract against DPPH. Leaves extracts shows higher percent absorbance than fruits extracts. However, the values for both extract are in close proximity to each other.
The antioxidant capacity for both extracts was dependent on the concentration tested. For concentration of $80 \mathrm{ppm}$, the antioxidant capacity reached 34.9 and $35.8 \%$ while for 20 ppm, the percentages were 29.8 and $31.0 \%$ for fruits and leaves extracts respectively. The percentages of antioxidant activity ranged from $29.8 \%$ to $35.8 \%$ from $20 \mathrm{ppm}$ to 80 ppm. It is possible to conclude that both fruits and leaves extracts have moderate antioxidant activity ranging from 20 ppm to $80 \mathrm{ppm}$. The phenolic compound which is 2,4bis(1,1-dimethylethyl)phenol in both extracts was probably respo-nsible for the positive result of DPPH scavenging activity. This compound is one of the flavanoid group and was reported to have the potential to inhibit free radical activity.

\section{Antibacterial Activity}

The inhibition zone was measured by diameter $(\mathrm{mm})$ and the inhibition strength were expressed by percent inhibition $(\%)$, where $\geq 70 \%$ is strong, 50 to $70 \%$ is moderate and $<50$ is weak inhibition [10]. Table 3 showed the inhibition strength of extracts on tested bacteria.

Leaves extracts showed moderate inhibition against $S$. aureus and weak inhibition against $E$. coli with $56.52 \%$ and $43.58 \%$ respectively. On the contrary, fruits extracts have moderate inhibition capacity against E. coli $(69.23 \%)$ and low inhibition capacity against $S$. aureus $(31.87 \%)$.

\section{CONCLUSION}

Both extracts contained similar major compounds which is 5-hydroxymeth 2-furancarboxaldehyde, 1-naphthyl ester acetoxyacetic acid, 2,4-bis(1,1-dimethylethyl)phenol and clindamycin with different percentage. Antioxidant assay showed that both extracts have moderate antioxidant capacity with $29.8 \%$ to $35.8 \%$ with concentration ranging from 20 to $80 \mathrm{ppm}$. In addition, antibacterial test showed that leaves and fruits extracts of A. elliptica has moderate inhibition against $S$. aureus and $E$. coli. 
Table 3. Inhibitory Activity of Fruits and Leaves Extracts of $\boldsymbol{A}$. elliptica.

\begin{tabular}{|c|c|c|c|c|}
\hline \multirow{2}{*}{ Compound } & \multicolumn{2}{|c|}{ Mean (mm) } & \multicolumn{2}{|c|}{ Percent Inhibition \% } \\
\hline & S. aureus & E. coli & S. aureus & E. coli \\
\hline Methanol & 7.00 & 8.00 & - & - \\
\hline Ampicilin & 7.00 & 12.00 & - & - \\
\hline Gentamicin & 23.00 & 26.00 & - & - \\
\hline Leaves extract & 13.00 & 11.33 & $56.52(++)$ & $43.58(+)$ \\
\hline Fruits extract & 7.33 & 18.00 & $31.87(+)$ & $69.23(++)$ \\
\hline
\end{tabular}

Note: + : Weak Inhibition $(<50)$

++ : Moderate Inhibition $(50-70 \%)$

+++ : Strong Inhibition $(\geq 70 \%)$

\section{CONFLICT OF INTEREST}

The authors confirm that this article content has no conflicts of interest.

\section{ACKNOWLEDGEMENTS}

We thank Universiti Teknologi MARA for the facilities provided and the financial support.

\section{REFERENCES}

Morton, J.P. 500 Plants of South Florida. Miami: E.A. Searmann Publishing, 1974.

[2] Sundriyal, M. and Sunriyal, R.C. Wild edible plants of Sikkin Himalaya; nutritive value of selective species. Econ. Botany 2001, $55,377-390$

[3] Jhonson, T. CRC Ethnobotany Desk Reference. CRC Press: Boca Raton, Florida, 1998, p. 65.
[4] Condit, R.; Perez, R.; Daguarre, N. Trees of Panama and Costa Rica. New Jersey: Princeton University Press, 2011, pp. 344-345.

[5] Corner, E.J.H. Wayside tress of Malaya. Singapore: Government Printing Office, 1952, p. 456.

[6] Koh, H. L.; Chua, T. K.; Tan, C. H. A Guide to Medicinal Plant, An Illustrated, Scientific and Medicinal Approach. Singapore: World Scientific Publishing, 2009; vol. 1, p. 67.

[7] Herbal Medicine Research Centre (HMRC) and Institute for Medicinal Research. Compendium of Medicinal Plants used in Malaysia. In: Ahmad Z., Lim H.H., Mohamed A.F.S. Eds.; Kuala Lumpur, Malaysia, 2002, p. 198.

[8] Ching, J.; Chua, T.K; Chin, L.C; Lau, A.J; Pang, Y.K; Jaya, J.M; Tan, C.H; Koh, J.L. $\beta$-amyrin from Ardisia elliptica is more potent than aspirin in inhibiting collagen-induced platelet aggregation. Indian J. Exp. Biol., 2010, 48, 275-279.

[9] Kobayashi, H.; Meija, de.E. The genus Ardisia: a novel source of health-promoting compounds and phytopharmaceuticals. $J$. Ethnopharmacol., 2004, 96, 347-354.

[10] Chan, Y.L. Antioxidant and antibacterial activity of leaves of Elingera species (Zingiberaceae) in Peninsular Malaysia. Food Chem., 2007, 104, 1586-1593.

(C) Alias et al.; Licensee Bentham Open.

This is an open access article licensed under the terms of the Creative Commons Attribution Non-Commercial License (http://creativecommons.org/licenses/by$\mathrm{nc} / 3.0 /$ ), which permits unrestricted, non-commercial use, distribution and reproduction in any medium, provided the work is properly cited. 